\title{
Measurement of the Infectivity of Trypanosoma cruzi in Faeces of Rhodnius by Comparison of Dose-response Curves
}

\author{
By A. S. MSHELBWALA* AND W. E. ORMEROD \\ London School of Hygiene and Tropical Medicine, Keppel Street, London, WC I ${ }_{7} H T$
}

(Received I3 July 1972; revised 7 September 1972)

\begin{abstract}
SUMMARY
The relationship between forms of Trypanosoma cruzi from the faeces of Rhodnius prolixus and the infection they produced in the blood of mice was studied. The number of motile forms in the inoculum showed little relation to intensity of parasitaemia, length of prepatent period or mortality rate, but was clearly related to the cumulative mortality and to the ID 50, which rose to a maximum at 6 weeks, remaining relatively constant thereafter. At some times amastigotes appeared to contribute to the infectivity. Subcutaneous inocula were more infective and more lethal than intraperitoneal. The appropriateness of different methods of assessing infectivity in protozoal infections is discussed.
\end{abstract}

\section{INTRODUCTION}

Phillips ( $1960 a$ ) demonstrated a clear quantitative relationship between the number of blood forms in an inoculum of Trypanosoma cruzi and the course of infection induced in experimental animals, and he described much of the basic experimental method by which the infectivity of $T$. cruzi could be studied (Phillips, I960 b; Phillips \& Bertram, 1967). Phillips also emphasized the need to adopt standardized techniques if strain differences in $T$. cruzi were to be studied: this work attempts to apply the general concepts and methods of Phillips to the study of infectivity for mice of forms found in the faeces of triatomid bugs (Hemiptera, Reduviidae).

In different parts of Latin America there are many differences in the symptoms, epidemiology and chemotherapy of Chagas's disease, which we felt might be explained in terms of strain differences. This investigation is a preliminary attempt to devise methods by which strains might be distinguished one from another; it seemed that differences in the infectivity of faecal forms were likely to constitute an important epidemiological factor.

Mazzotti (I940), Pizzi \& Prager (I953) and da Silva \& Nussenzweig (I953) had shown an association between the number of organisms injected and the length of the prepatent period, number of parasites in the blood and death rates of infected animals, but the differences were not examined statistically.

Since Phillips's work, other methods of assessing the infectivity of protozoal parasites have been developed. Lumsden, Cunningham, Webber, van Hoeve \& Walker (1963) estimated the infectivity of suspensions of Trypanosoma brucei by successive dilution to determine the point where $63 \%$ of inoculated mice became infected (ID63), corresponding to an average inoculum of one infective trypanosome per mouse. Whereas this procedure may be useful in assessing the infectivity of strains which are as virulent as the one used by Lumsden and his colleagues (which produced parasitaemia in 3 days after inoculation of a single trypanosome), it is likely to be less useful with strains which produce a chronic

\footnotetext{
* Present address: Nigerian Institute for Trypanosomiasis Research, Kaduna, Nigeria.
} 
infection. Even the most virulent strains of $T$. cruzi, inoculated at 1000 trypanosomes per mouse, seldom produce parasitaemia by 8 days. In these circumstances host resistance may be as important in determining the result of the experiment as any property of the parasite.

Warhurst \& Folwell (I968) used the prepatent period, or more precisely the 'pre-2\% period' (the period between intravenous inoculation of parasites and the infection of $2 \%$ of the erythrocytes), in mice as a measure of infectivity and showed that it was related linearly to the log number of parasites of Plasmodium berghei inoculated intravenously. The method of Overdulve \& Antonisse (1970), which eliminates some of the effects of host resistance by using large inocula, requires a high and constant rate of reproduction in the blood as occurred in the strain of Babesia rodhaini which they used. Although high and constant rates of reproduction obtain in many bacterial and viral infections (Meynell \& Meynell, 1958), they are rarer in protozoal infections where the life-cycles tend to be complicated and the parasitaemias fluctuating. These three methods are probably valid only for the study of protozoal infections produced by strains adapted artificially in the laboratory. Parasitaemia in Trypanosoma cruzi infection is preceded, as in most other protozoal blood infections in whole or in part, by a visceral phase which acts as an important source of blood parasites; thus blood forms are not increased solely by binary fission nor does multiplication normally occur at a constant rate. Thus there is a delay in the establishment of parasitaemia which may enable the host to build up resistance to the infection.

The method we have used to assess infectivity consists in the comparison of log doseresponse curves (Trevan, 1927; Gaddum, 1933). It has been used for many types of biological assay including the assessment of drug resistance in trypanosomes (Ormerod, 1952) and is entirely suitable for the study of infectivity because it requires no previous suppositions of how the inoculum produces the infection.

\section{METHODS}

Protozoa. Two strains of Trypanosoma cruzi were used.

The 'Sonya strain' was isolated in São Paulo, Brazil in 1955 (Garnham, 1956). From the date of its isolation to the time when it was used by Phillips in 1956-7 it was transmitted mainly by passage of blood by syringe between mice, but since that time it has been maintained serially by feeding triatomid bugs on infected mice and inoculating the bug faeces into uninfected mice; the result has been a slight decrease in virulence so that, irrespective of the number of flagellates inoculated, parasitaemia now occurs in 20 (10 to 15 ) days and death in 3 to 5 ( 2 to 3 ) weeks, the figures in parentheses being those of Garnham (1956) and Phillips (1960a); a few of our mice recovered from infection, whereas those observed by Garnham invariably died; terminal oedema continued to be a marked feature. The 'Peru strain' was isolated in I 963 by Dr Felix Náquira in Areqipa, Peru, and maintained in the Universidad de Santiago de Chile. In the same year it was given to Dr Frans Goble (Nussenzweig \& Goble, I966); he gave it to Dr P. D. Marsden of this School who showed that a single trypanosome could produce an infection from which the mice died within a period of 30 days, infections with 1000 trypanosomes being invariably lethal (Marsden, I971 $a$ ). During our work the prepatent period was 8 to I 4 days and death occurred within 3 to 4 weeks irrespective of the size of the inoculum. Previous workers have transmitted this strain by syringe passage of blood, but we maintained it by inoculating mice with the dejecta of Rhodnius prolixus. 
Vector. The strain of Rhodnius prolixus was isolated in Venezuela in I9I3 and maintained in this School; it was the same strain that Phillips had used. Infected bugs were maintained at $28{ }^{\circ} \mathrm{C}$. The techniques for handling vector and parasite, and for transmitting the infection were essentially those developed by Phillips ( $1960 a$ ).

Procedure. Bugs were infected by feeding either on a single infected mouse or on infected blood through a mouse skin membrane (Chapman \& Ormerod, 1966). Batches of first-instar larvae were generally used for the initial feed on infective material. Faecal samples were released voluntarily by the bugs on feeding, and bugs could be kept as donors of infective material for several months. Faecal material from a group of bugs infected from the same blood or from the same animal at the same time was pooled, diluted appropriately with $3.8 \%$ sodium citrate in physiological saline and counted in a haemocytometer; the proportion of metacyclic forms was determined by phase contrast microscopy or by the examination of stained smears.

In previous work metacyclic trypomastigotes have always been distinguished from epimastigotes in stained smears. While this is essential for establishing the position of the kinetoplast on strict morphological criteria, it is often difficult in practice to make the distinction because of the presence of large amounts of pigment and other debris in the faeces, so that even under ideal conditions there is always doubt as to how a proportion of the forms should be classified. A clear-cut distinction can be made on ground of motility (as in Table I), since metacyclic trypomastigotes undulate through the whole of their length whereas epimastigotes (which vary greatly in shape) are either rigid throughout a proportion of the posterior end or bulbous at the posterior end. If stained preparations are examined (as in Table 2) different proportions result; we believe that the former method is better.

Vertebrate hosts. Mice of the To strain, 3 to 4 weeks old, weighing 10 to I $5 \mathrm{~g}$, were used except in the reinoculation experiment where the ages of controls were matched with those of the experimental mice. They were kept in one room maintained at $24{ }^{\circ} \mathrm{C}$. Fresh tail blood of infected mice was first examined microscopically $(\times 450)$ I (Peru strain) or 2 (Sonya strain) weeks after inoculation, and thereafter daily for Io weeks; up to Ioo fields were examined unless trypanosomes were seen earlier. All infected mice were moved to another cage to avoid infection through cannibalism. After 7 weeks mice which remained persistently negative were tested by xenodiagnosis with uninfected Rhodnius prolixus; none tested thus showed infection except in the reinoculation experiment (Table $4 a$ ) where two infections not diagnosed by blood examination were disclosed.

Treatment of data. Results of infectivity experiments were recorded as numbers of mice infected out of groups of (usually) Io. Dead mice were removed daily from the cages and their numbers recorded. For each experiment the infectivity was determined by establishing the $\log _{10} \mathrm{ID}_{50}$, that is to say the logarithm of the dose (i.e., number of organisms) which infected $50 \%$ of the mice. The log dose-percentage infected curves were shown by Moran's method to be, on average, flatter than those predicted by the Poisson distribution (Meynell \& Meynell, 1970). A satisfactory fit was, however, obtained by assuming that, in each experiment, the 'logit' (Armitage, I97I) of the proportion killed was linearly related to log dose, the lines for different experiments being parallel. The lines were fitted by maximum likelihood, using the facilities of the University of London Computer Centre. 


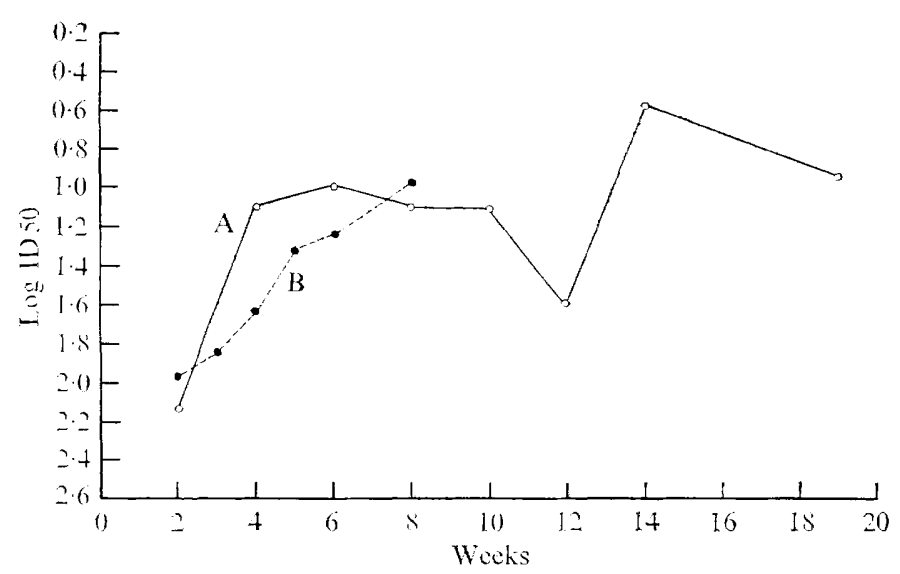

Fig. I. Relationship of infectivity of motile flagellates with time in bugs infected with (A) Sonya strain and (B) Peru strain.

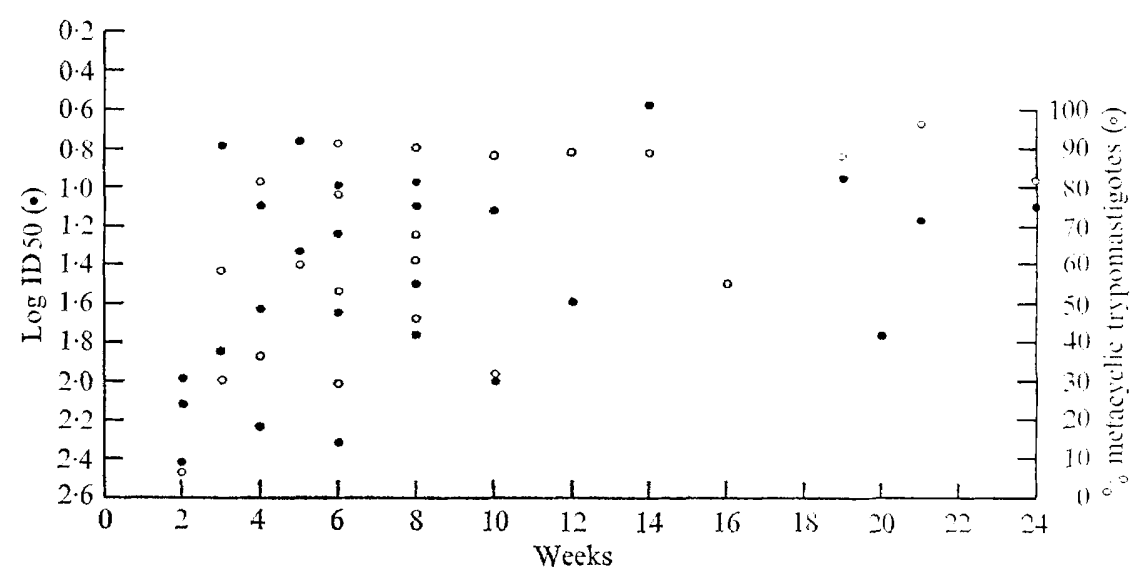

Fig. 2. Relationship of infectivity of motile flagellates and percentage of metacyclic trypomastigotes with time. Combined results of all experiments in which intraperitoneal inoculation was used.

\section{RESULTS}

Variation of infectivity of faecal forms with duration of infection in the bug

The infectivity of both strains began at a low level when bugs first showed flagellates in the faeces, rose to a peak and levelled out thereafter. The general pattern is shown in Fig. I, where only two experiments are followed, but the degree of variation between different experiments is demonstrated in Fig. 2, which includes results obtained in all experiments using intraperitoneal inoculation.

\section{Relation of infectivity to percentage of metacyclic trypomastigotes}

The rapid rise in infectivity between the second and fourth weeks followed, in general, a rise in the proportion of metacyclic forms and the levelling out of the infectivity/time curve (Fig. I) appeared to follow the establishment of a maximum percentage ( 80 to $90 \%$ ) of metacyclic forms (Table 2; Fig. 3a). 

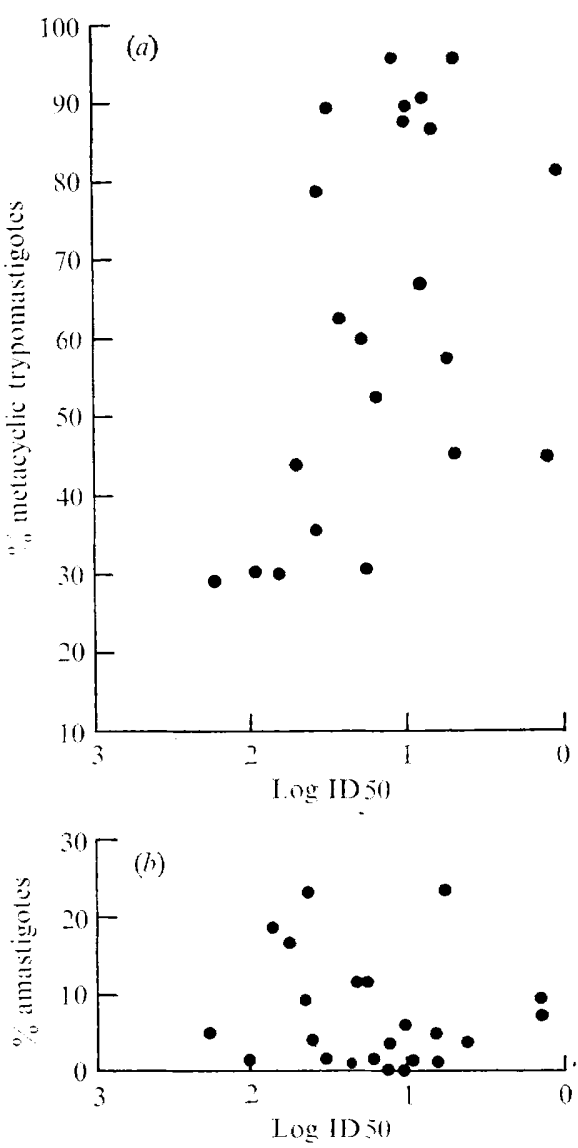

Fig. 3. Relationship of percentage of metacyclic trypomastigotes $(a)$ and amastigotes $(b)$ to infectivity.

Numbers of amastigotes in the inoculum and their probable infectivity

Substantial numbers of amastigotes were seen in stained preparations of faeces at different stages of the infection (Table 2); at 2 weeks there were more amastigotes present than metacyclic forms. In experiments SI 4, PI and P7 (Table I) infection occurred despite the apparent absence of metacyclic forms from the fresh faecal preparation. In stained smears the faeces of $\mathrm{P7}$ (Table 2 ) contained $\mathrm{I} 6 \%$ amastigotes and $84 \%$ epimastigotes, but metacyclic forms were not seen. While it is likely that amastigotes are infective for mice, Fig. $3(b)$ shows no apparent trend in infectivity of inocula in relation to the proportion of amastigotes which suggests that their infectivity is substantially less than that of the metacyclic forms.

\section{Relation of numbers of motile forms to mortality of mice}

At each dose level there was little systematic difference between the mortalities of infected mice over a given period (Table 3). With two exceptions (when a group of ro mice all succumbed after subcutaneous inoculation) survival lay between 9 and $20 \%$. However, with the Sonya strain (Fig. 4), deaths occurred sooner as the dose was increased but the rate at which this occurred decreased as the dose was increased. The same effects were seen with the Peru strain but were less clear cut, since the curves tended to overlap and to be 'cut off' by the higher mortality. 
Table I. The proportion of infected animals resulting from intraperitoneal (IP) and subcutaneous (SC) inoculation of flagellates from pooled faeces of bugs at different stages of infection.

The proportion of metacyclic trypomastigotes was estimated by phase-contrast microscopy. Infectivity is given in terms of $\log _{10} \mathrm{ID}_{50}$ together with $95 \%$ confidence limit computed from the infection results and numbers inoculated. Values below zero (corresponding to $\operatorname{ID}_{50}=I$ ) are shown in brackets; the lowest possible value corresponding to $100 \%$ infectivity is -0.16 .

\begin{tabular}{|c|c|c|c|c|c|c|c|c|c|c|c|}
\hline \multirow{2}{*}{\multicolumn{3}{|c|}{$\begin{array}{l}\text { Expt no. } \\
\text { strain route of } \\
\text { inoculation }\end{array}$}} & \multirow{3}{*}{$\begin{array}{c}\text { Weeks } \\
\text { in } \\
\text { bug } \\
2\end{array}$} & \multirow{3}{*}{$\begin{array}{l}\text { Meta- } \\
\text { cyclics } \\
(\%) \\
-\end{array}$} & \multicolumn{4}{|c|}{ No. flagellates inoculated } & \multirow[b]{2}{*}{$\begin{array}{c}\text { Infectivity } \\
\log _{10} I_{50} \\
M\end{array}$} & \multicolumn{2}{|c|}{$\begin{array}{l}95 \% \text { confidence } \\
\text { interval }\end{array}$} \\
\hline & & & & & \multicolumn{4}{|c|}{${ }^{\text {I }}$ Proportion of mice infected ${ }^{1000}$} & & \multirow{2}{*}{$\begin{array}{c}M+2 S E \\
(\mathrm{M}) \\
2.60\end{array}$} & \multirow{2}{*}{$\begin{array}{c}M-2 S E \\
(M) \\
I \cdot 64\end{array}$} \\
\hline (a) & s3 & \multirow[t]{8}{*}{ IP } & & & $0 / 9$ & $1 / 10$ & $4 / 10$ & - & $2 \cdot 12$ & & \\
\hline & $\mathrm{S} 4$ & & 4 & - & $2 / 10$ & $3 / 10$ & $9 / 10$ & - & $I \cdot I O$ & $I \cdot 52$ & 0.68 \\
\hline & s5 & & 6 & - & $2 / 10$ & $4 / 10$ & $8 / 9$ & $10 / 10$ & I.OO & I 42 & 0.58 \\
\hline & $s 6$ & & 8 & - & $2 / 10$ & $3 / 10$ & $9 / 10$ & -- & $I \cdot 10$ & $1 \cdot 52$ & 0.68 \\
\hline & s7 & & 10 & - & $0 / 10$ & $4 / 10$ & $9 / 9$ & - & $I \cdot I I$ & $1 \cdot 53$ & 0.69 \\
\hline & s8 & & I 2 & -- & $1 / 10$ & $1 / 10$ & $7 / 10$ & $10 / 10$ & $I \cdot 60$ & $2 \cdot 00$ & $I \cdot 20$ \\
\hline & s9 & & 14 & -- & $3 / 10$ & $6 / 10$ & $10 / 10$ & - & 0.58 & 1.00 & 0.16 \\
\hline & SII & & 19 & -- & $4 / 15$ & $8 / 19$ & $15 / 17$ & - & 0.96 & $I \cdot 28$ & 0.64 \\
\hline \multirow{6}{*}{ (b) } & sio & \multirow[t]{6}{*}{ IP } & 2 & $7 \cdot 7$ & $0 / 9$ & 0/10 & $6 / 10$ & - & I. 99 & $2 \cdot 45$ & $\mathrm{I} \cdot 53$ \\
\hline & $\sin 2$ & & 3 & 50 & $1 / 10$ & $0 / 10$ & $5 / 8$ & - & $1 \cdot 85$ & $2 \cdot 33$ & $1 \cdot 37$ \\
\hline & SI3 & & 4 & 65 & $0 / 5$ & $1 / 10$ & $8 / 10$ & - & 1.63 & $2 \cdot 07$ & $I \cdot 19$ \\
\hline & Si 5 & & 5 & 50 & $1 / 10$ & $2 / 7$ & $7 / 9$ & 一 & $I \cdot 34$ & $I \cdot 80$ & 0.88 \\
\hline & si 7 & & 6 & 70 & $0 / 9$ & $4 / 10$ & $6 / 7$ & - & $I \cdot 25$ & $I \cdot 69$ & $0.8 \mathrm{I}$ \\
\hline & sig & & 8 & 63 & $1 / 10$ & $4 / 8$ & 9/10 & $10 / 10$ & 0.99 & $I \cdot 43$ & 0.55 \\
\hline \multirow{6}{*}{ (c) } & PI & \multirow[t]{6}{*}{ IP } & 2 & 0 & $0 / 10$ & o/10 & $3 / 10$ & - & $2 \cdot 42$ & $2 \cdot 98$ & $\mathrm{I} \cdot 86$ \\
\hline & P2 & & 3 & 75 & $1 / 10$ & 6/10 & $10 / 10$ & - & 0.79 & $\mathrm{I} \cdot 2 \mathrm{I}$ & 0.37 \\
\hline & P3 & & 4 & 78 & $8 / 10$ & $8 / 10$ & $10 / 10$ & - & {$[-0.26]$} & 0.14 & {$[-0.76]$} \\
\hline & P4 & & 6 & 40 & $0 / 10$ & $0 / 10$ & $4 / 10$ & - & $2 \cdot 26$ & $2 \cdot 76$ & $I \cdot 76$ \\
\hline & P5 & & 8 & 89 & $0 / 10$ & $0 / 9$ & $10 / 10$ & 一 & $I \cdot 50$ & $1 \cdot 94$ & I'06 \\
\hline & P6 & & IO & 33 & $0 / 10$ & $0 / 10$ & $6 / 10$ & 9/10 & $2 \cdot 0 \mathrm{I}$ & $2 \cdot 43$ & $\mathrm{I} \cdot 59$ \\
\hline \multirow{5}{*}{ (d) } & P7 & \multirow[t]{5}{*}{$\mathrm{SC}$} & 2 & o & $0 / 10$ & $2 / 10$ & $6 / 10$ & - & $I \cdot 75$ & $2 \cdot 19$ & $\mathrm{I} \cdot 3 \mathrm{I}$ \\
\hline & P8 & & 4 & 88 & 9/10 & $10 / 10$ & $10 / 10$ & 一 & {$[-0.96]$} & {$[-0.08]$} & {$[-\mathrm{I} \cdot 84]$} \\
\hline & P9 & & 6 & 50 & $3 / 10$ & ro/Io & $10 / 10$ & - & 0.13 & 0.57 & {$[-0.31]$} \\
\hline & PI2 & & 8 & 80 & $0 / 10$ & $2 / 10$ & $10 / 10$ & - & $I \cdot 3 I$ & $\mathrm{I} \cdot 73$ & 0.89 \\
\hline & \multicolumn{10}{|c|}{ Infectivity of flagellates from bugs infected independently } & \\
\hline \multirow[t]{6}{*}{ (e) } & S1 4 & IP & 4 & 0 & o/Io & I $/ 9$ & $3 / 10$ & 一 & $2 \cdot 25$ & $2 \cdot 81$ & $I \cdot 69$ \\
\hline & s2 & & 5 & - & $1 / 9$ & $6 / 10$ & $9 / 9$ & - & 0.78 & $I \cdot 20$ & 0.36 \\
\hline & si 6 & & 6 & 65 & $1 / 10$ & $2 / 10$ & $6 / 10$ & 一 & $I \cdot 64$ & 2.06 & $1 \cdot 22$ \\
\hline & s1 8 & & 8 & 90 & $1 / 9$ & $5 / 8$ & $8 / 8$ & $9 / 9$ & 0.78 & $I \cdot 21$ & 0.29 \\
\hline & SI & & 20 & - & $0 / 10$ & $2 / 9$ & $5 / 9$ & - & $1 \cdot 78$ & $2 \cdot 24$ & $I \cdot 32$ \\
\hline & & & & Infect & ity of & same i & cula by & ferent $\mathrm{r}$ & routes & & \\
\hline \multirow[t]{4}{*}{$(f)$} & S22 & IP & $2 \mathrm{I}$ & 98 & $0 / 10$ & $4 / 10$ & $9 / 10$ & $10 / 10$ & I 19 & I 59 & 0.79 \\
\hline & S23 & $\mathrm{SC}$ & 21 & 98 & $\mathrm{I} / \mathrm{IO}$ & $6 / 10$ & $10 / 10$ & Io/ 10 & 0.79 & $I \cdot 21$ & 0.37 \\
\hline & PIO & IP & 24 & 82 & $5 / 10$ & $8 / 10$ & $10 / 10$ & $10 / 10$ & 0.13 & 0.57 & {$[-0.31]$} \\
\hline & PII & $\mathrm{SC}$ & 24 & 82 & $10 / 10$ & $10 / 10$ & $10 / 10$ & $10 / 10$ & & & \\
\hline
\end{tabular}

\section{The effect of different routes of inoculation on infection rate and mortality}

Given a high percentage of metacyclic forms in the inoculum, the levels of infectivity tended to be higher when injection was made subcutaneously than intraperitoneally (Table I $a-e$ ). The effect was shown most clearly with infectivity of the Peru strain (Fig. 5) and the cumulative mortality that it produced (Fig. 6). Although these results were consistent and were obtained with both strains, they consisted of pooled results of experiments 


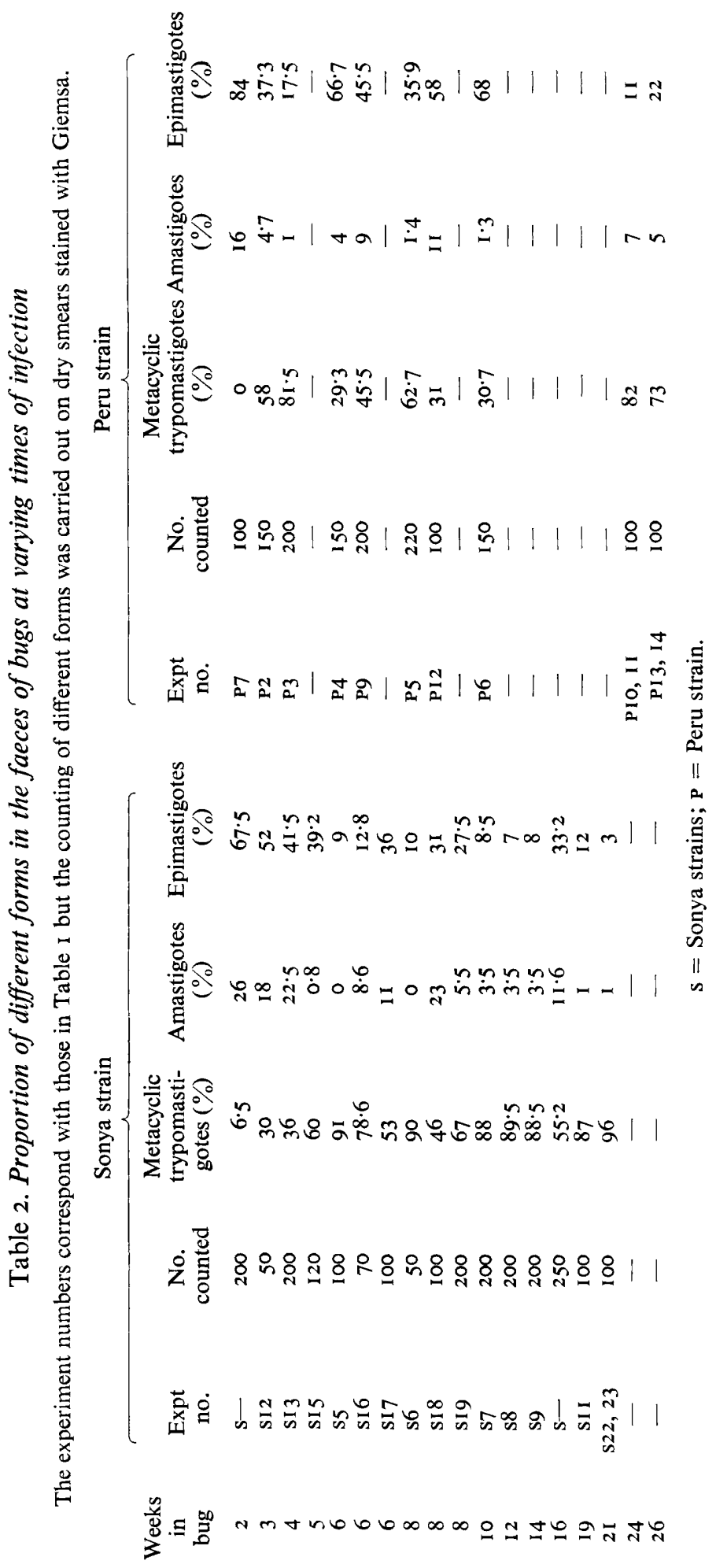




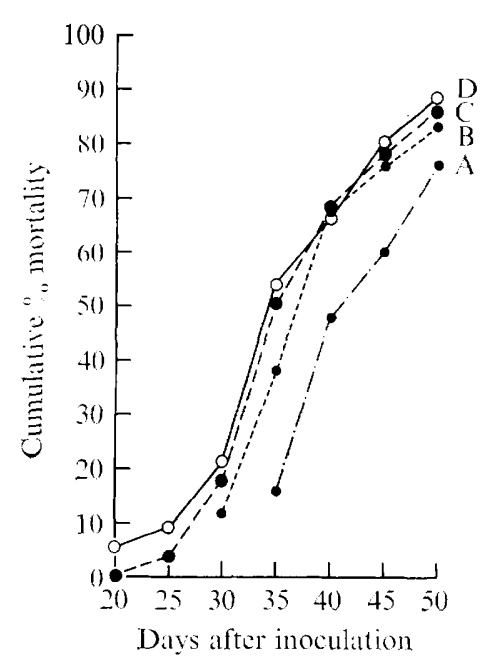

Fig. 4

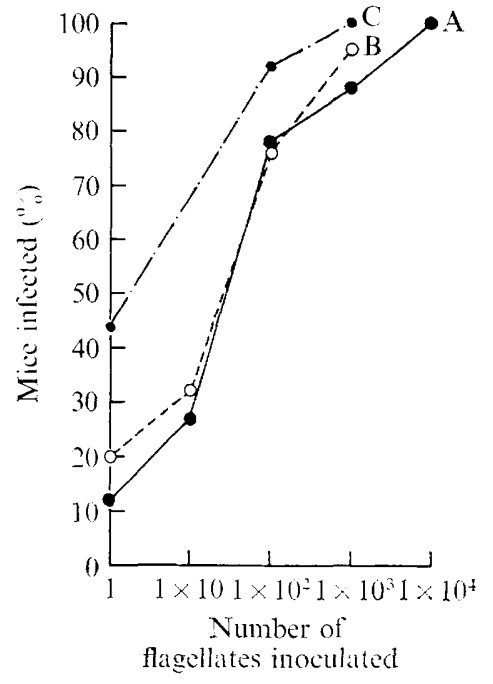

Fig. 5

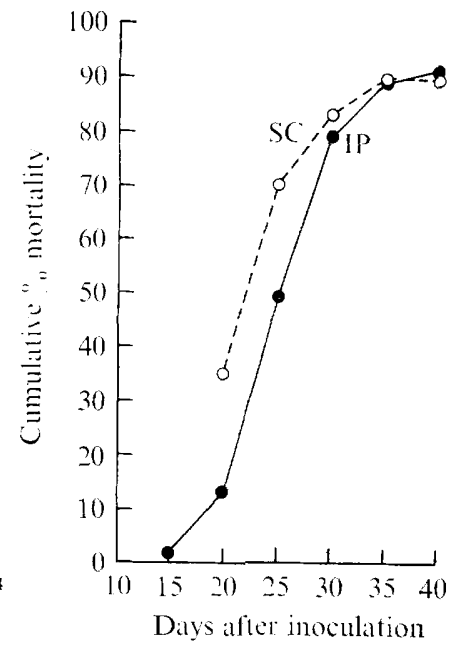

Fig. 6

Fig. 4. Increase in cumulative percentage mortality with time (i.e. the rapidity with which mice died) when infected with a pooled suspension of Sonya strain. Inocula diluted to the following theoretical numbers of flagellates/mouse: A, 1; B, 10; C, 100; D, 1000.

Fig. 5. Effect of variation of inoculum size on the infection rate in mice. A, Sonya strain intraperitoneal inoculation; B, Peru strain intraperitoneal inoculation; C, Peru strain subcutaneous inoculation.

Fig. 6. Relative increase with time of cumulative percentage mortality of mice receiving 100 flagellates from a pooled suspension of Peru strain. IP, Intraperitoneal inoculation; SC, subcutaneous inoculation.

in which the inoculum was not necessarily from the same source so that comparison of the two routes of infection was not strictly justifiable. A second experiment was therefore carried out in which inocula derived from the same source and containing a high percentage of metacyclic trypomastigotes were given. The increased infectivity by the subcutaneous route again occurred with both strains (Table I $f$ ), but no quantitative result was obtained with the Peru strain because all the mice injected subcutaneously (experiment PII) became infected.

\section{Relation between number of motile forms and infection rate}

The relationship between the log number of forms inoculated and the infection rate is shown in Fig. 5. The most useful part of the dose range lies between Io and roo motile forms, probably because the strains used are highly virulent having been serially passaged in the laboratory for a number of years. Fig. 5 shows that even higher levels of infectivity can be obtained with the subcutaneous route of inoculation, giving, with the Peru strain, a linear increase with inocula of I to I oo motile forms and a $45 \%$ infection rate when the inoculum contained theoretically a single trypanosome. As no clear relationship between host resistance and infectivity emerged from these experiments, except in the difference displayed between the two routes of inoculation, reinoculation experiments were undertaken.

\section{Reinoculation of uninfected animals}

Two experiments were carried out to find the degree of resistance of animals which had previously been inoculated; the results are seen in Table 4 . 
Table 3. Mean survival times and percentage survival (at 40 days for Peru and 50 days for Sonya strain) of mice infected at different dose levels by intraperitoneal $(I P)$ and subcutaneous (SC) inoculation

\begin{tabular}{|c|c|c|c|c|}
\hline $\begin{array}{l}\text { No. forms } \\
\text { inoculated }\end{array}$ & $\begin{array}{c}\text { Mice } \\
\text { infected }\end{array}$ & $\begin{array}{c}\text { Mean } \\
\text { survival time } \\
\text { (days) }\end{array}$ & $\begin{array}{l}\text { Range of } \\
\text { survival time } \\
\text { (days) }\end{array}$ & $\begin{array}{c}\text { Survival at } \\
\text { stated period } \\
(\%)\end{array}$ \\
\hline Peru strain IP & & & & 40 days \\
\hline I & $14 / 70$ & $25 \cdot I$ & $2 \mathrm{I}-34$ & $14 \cdot 3$ \\
\hline 10 & $22 / 69$ & $25 \cdot 7$ & $20-35$ & $9 \cdot I$ \\
\hline 100 & $53 / 70$ & 24.9 & $15-39$ & $9 \cdot 4$ \\
\hline 1000 & $19 / 20$ & $23 \cdot 7$ & $17-34$ & $15 \cdot 8$ \\
\hline Peru strain SC & & & & 40 days \\
\hline I & $22 / 50$ & $24 \cdot 7$ & $2 \mathrm{I}-34$ & I 3.6 \\
\hline IO & $34 / 50$ & $23 \cdot 0$ & $19-3 I$ & $8 \cdot 8$ \\
\hline 100 & $46 / 50$ & $23 \cdot 0$ & $18-35$ & $10 \cdot 9$ \\
\hline 1000 & $10 / 10$ & $19 \cdot 6$ & IO-28 & 0 \\
\hline Sonya strain IP & & & & 50 days \\
\hline I & $25 / 2 I 5$ & $40 \cdot 3$ & $33-50$ & 24.0 \\
\hline IO & $59 / 215$ & $36 \cdot I$ & $26-47$ & $17 \cdot 2$ \\
\hline 100 & $175 / 226$ & $35 \cdot 6$ & $20-50$ & $16 \cdot 6$ \\
\hline 1000 & $52 / 59$ & $34 \cdot 6$ & $20-50$ & I I 5 \\
\hline 10000 & $17 / 17$ & $32 \cdot 4$ & $27-38$ & $17 \cdot 6$ \\
\hline Sonya strain SC & & & & 50 days \\
\hline I & $1 / 10$ & $(40)$ & - & - \\
\hline IO & $6 / 10$ & $40 \cdot 6$ & $35-47$ & $16 \cdot 7$ \\
\hline 100 & $10 / 10$ & $33 \cdot 7$ & $29-37$ & 0 \\
\hline 1000 & $10 / 10$ & $28 \cdot 7$ & $25-32$ & 20.0 \\
\hline
\end{tabular}

Table 4. Results of reinoculation experiments

(a) Mice which had overcome their infection.

(b) Mice which had been previously inoculated but had failed to show infection.

No. of flagellates inoculated

Expt no. strain route of inoculation

(a) s2o IP controls S21 IP infection overcome

P SC controls

$\mathrm{P}$ SC infection overcome

(b) s28 IP controls S29 SC controls s26 IP inoc. no infection

s27 SC inoc. no infection

Metacyclics
$(\%)$

86

86

72

72

88

88

88

88
Proportion mice infected

IO $100 \quad 1000$

$0 / 10$

$0 / 9$

9/10

$3 * / 10$

9/10

$0 / 10$

$-$

$-$

$10 / 10$

$6 \longdiv { 9 }$

5/5

$5 / 5$

I $2 / 13$

I $3 / 13$

* Two mice shown by Xenodiagnosis to be infected.

In experiment $(a)$ mice which had become infected but had overcome their infection were reinoculated. Previously uninfected mice of the same age and weight were infected with similar inocula. The reinoculated animals showed a substantial degree of resistance; the controls did not show any more resistance than mice used in our other experiments despite their greater age.

However, in experiment $(b)$, mice which had previously been inoculated but had not become infected gave no evidence of resistance to reinfection. 


\section{DISCUSSION}

We have found great similarity between infections, both in intensity and in mortality, produced by doses ranging over four orders of magnitude; the only satisfactory differences produced were in infectivity and in cumulative mortality rates (i.e. longevity after infection). In this work the latter function although interesting has not proved particularly useful; the former, however, has been of value in demonstrating various conditions which affect the infectivity of faecal forms.

Of these conditions the most noteworthy is the route of inoculation; Trypanosoma cruzi differs from $T$. bruce $i$ which is more infective when introduced intraperitoneally (unpublished observations). Hewitt, Entwhistle \& Gill (I963) found that large inocula of blood trypomastigotes of $T$. cruzi also gave more virulent infections more consistently when inoculated subcutaneously, although Marsden (1967), who used smaller doses of blood forms of the Peru strain, found little difference between the two routes.

We found considerable variation in the proportions of metacyclic trypomastigotes and epimastigotes in the faeces. It is usually assumed that the metacyclic trypomastigote is the only infective element, the epimastigote being non-infective; our observations generally agree with these assumptions but suggest also the possibility that amastigotes may be infective.

Dias (1934) found that the whole gut was infective throughout the infection in the bug, which he attributed to the survival of blood trypomastigotes in the midgut overlapping in time with the formation of metacyclic trypomastigotes. He also showed that amastigotes often preceded the formation of metacyclic trypomastigotes, but did not attribute infectivity to them nor did he find them in the faeces.

Phillips ( $1960 b$ ) excluded the presence of persistent blood forms as a source of infection in faecal specimens and stated that amastigotes were not a source of infection, although they did occasionally occur. This, however, has not been our experience; stained smears of faecal material sometimes showed as many amastigotes as trypomastigotes and we cannot exclude their potential infectivity, which could account for our observation that faeces in which no trypomastigotes could be found proved infective for mice (Tables $I c-e ; 2$ ). This work was planned on the assumption that amastigotes were not likely to be important infective forms; their possible significance only became apparent as a result of the discrepancies in our final results. We now believe that the faecal production of amastigotes may be important in the transmission of Trypanosoma cruzi and should be studied specifically.

Although the intensity of infection, mortality and length of the prepatent period were similar whatever the size of the inoculum, we believe that the range of infectivity demonstrated in this work indicated some degree of resistance of mice to infection with Trypanosoma cruzi. This resistance does not appear to be based solely on the formation of antibodies, because of the ease with which animals, which had not become infected after the initial inoculation, succumbed to challenge; animals which had thrown off their infection were in general resistant to challenge. Probably the two strains are too virulent, as are laboratory strains of $T$. brucei, to act as satisfactory experimental models for the study of natural transmission of organisms. Less virulent, more recently isolated strains would be more suitable, and could be studied by the same methods, except that larger inocula and xenodiagnosis might be necessary.

With strains as virulent as these, it is possible that we could have obtained satisfactory measurements of infectivity by using the method of Lumsden et al. (I963). However, we 
regard this degree of virulence as artificial and also believe that there are other objections to the use of Lumsden et al. (I963) method, as follows.

(i) An implicit assumption is that the dose-response curves should be exponential, as implied by the first term of the Poisson distribution. The curves which we obtained were on the whole flatter than this, indicating a heterogeneity of the mice which we believe to be due to the development of immunity when the prepatent period is prolonged. If this is so, it is likely that dose-response curves obtained from more recently isolated strains would show an even more marked deviation from the Poisson model.

(ii) ' $\mathrm{ID}_{63}$ ' is widely used today as equivalent to an 'infective trypanosome unit' and inocula given to a variety of hosts are thus standardized. We do not think that this conveys any more useful information than is given by the number and type of organisms injected, since it cannot be assumed that the resistance of, say, man or cow to infection is in any way related to the resistance of the mice by means of which the units were obtained.

We therefore believe that results obtained by estimating $\mathrm{ID}_{63}$ may be misleading. This, however, can be avoided if the $\mathrm{ID}_{50}$ is used, and, since there is no connotation of 'single infective organism' involved, it is unlikely to be used as an absoute 'infectivity unit' but rather as a means of comparison.

We thank Professor P. Armitage for his advice and for the statistical analysis. This work was supported by grants from the Overseas Development Administration of the Foreign and Commonwealth Office and from the Rockefeller Foundation.

\section{REFERENCES}

Armitage, P. (1971). Statistical Methods in Medical Research, p. 359. Oxford: Blackwell Scientific Publications.

Chapman, J. M. \& Ormerod, W. E. (1966). The survival of Toxoplasma in infected mosquitoes. Journal of Hygiene, Cambridge 64, 347-355.

DIAS, E. (1934). Estudios sôbre o Schizotrypanum cruzi. Memorias do Instituto Oswaldo Cruz 28, I-I 10.

GADDUM, J. H. (1933). Reports on biological standards. III. Methods of biological assay depending on a quantal response. Medical Research Council Special Report Series 183, I-46.

Garnham, P. C. C. (1956). Isolation of a new strain of Trypanosoma cruzi. Transactions of the Royal Society of Tropical Medicine and Hygiene 5o, 613.

Hewitt, R., EnTwhistle, J. \& Gill, E. (1963). Quantitative determinations of critical mortality periods in untreated and treated infections with the B strain of Trypanosoma cruzi in mice. Journal of Parasitology 49, 22-30.

Lumsden, W. H. R., Cunningham, M. P., Webber, W. A. F., van Hoeve, K. \& Walker, P. J. (1963). A method for the measurement of the infectivity of trypanosome suspensions. Experimental Parasitology 14, 269-279.

MARSDEN, P. D. (I97I $a$ ). Trypanosoma cruzi infections in CFI mice. I. Mortality with different doses of trypanosomes. Annals of Tropical Medicine and Parasitology 6r, 57-6r.

Marsden, P. D. (I97I b). Trypanosoma cruzi infections in CFI mice. II. Infections induced by different routes. Annals of Tropical Medicine and Parasitology 6r, 62-67.

MAZzotTI, L. (1940). Effects of inoculating small and large numbers of Trypanosoma cruzi in mice. American Journal of Hygiene $\mathbf{3}^{\mathrm{I}}(\mathrm{C}), 86-9 \mathrm{I}$.

MeYnell, G. G. \& MeYNell, E. W. (1958). The growth of micro-organisms in vivo with particular reference to the relation between dose and latent period. Journal of Hygiene 56, 323-346.

Meynell, G. G. \& Meynell, E. W. (1970). Theory and Practice in Experimental Bacteriology, and edn, pp. I 85-19I. London: Cambridge University Press.

NusSENZWEIG, V. \& GoBle, F. C. (I966). Further studies on the antigenic constitution of strains of Trypanosoma (Schizotrypanum) cruzi. Experimental Parasitology 18, 224-230. 
ORMERoD, W. E. (1952). A study of resistance to Antrycide in a strain of Trypanosoma equiperdum. British Journal of Pharmacology 7, 674-684.

Overdulve, J. P. \& ANTONisse, H. W. (1970). Measurement of the effect of low temperature on protozoa by titration. I. A mathematical model for titration, using prepatent period or survival time; with a discussion of the method of the ID63. Experimental Parasitology 27, 310-322.

Phillips, N. R. (1960a). Experimental studies on the quantitative transmission of Trypanosoma cruzi: considerations regarding the standardization of materials. Annals of Tropical Medicine and Parasitology 54, 60-70.

Phililps, N. R. (1960 b). Experimental studies on the quantitative transmission of Trypanosoma cruzi: aspects of the rearing, maintenance and testing of vector material, and of the origin and course of infection in the vector. Annals of Tropical Medicine and Parasitology 54, 397-4I4.

Phillips, N. R. \& Bertram, D. S. (1967). Laboratory studies of Trypanosoma cruzi infections. Journal of Medical Entomology 4, I68-I74.

Pizzi, P. T. \& Prager, S. R. (1953). Estabilizacion de la virulencia de una cepa de Trypanosoma cruzi por pasaje seriado en ratones de constitucion genetica uniforme: analisis cuantitivo del curso de la infeccion. Biologica Santiago 16-17, 3-12.

DA Silva, L. H. P. \& NussenzweIG, G. (1953). Sôbre una cepa de Trypanosoma cruzi altamente virulenta para o camundongo branco. Folia Clinica et Biologica, São Paulo 20, 191-207.

Trevan, J. W. (1927). The error of determination of toxicity. Proceedings of the Royal Society B roI, 483-5I4.

WARHURST, D. C. \& Folwell, R. O. (1968) Measurement of the growth rate of the erythrocytic stages of Plasmodium berghei and comparisons of the potency of inocula after various treatments. Annals of Tropical Medicine and Parasitology, 62, 349-360. 